\title{
Simulating the Storage and the Blockage Effects of Buildings in Urban Flood Modeling
}

\author{
Chen-Jia Huang ${ }^{1}$, Ming-Hsi Hsu ${ }^{1,2, *}$, Albert S. Chen ${ }^{3}$, and Chien-Hsun Chiu ${ }^{1}$ \\ ${ }^{1}$ Department of Bioenvironmental Systems Engineering, National Taiwan University, Taipei, Taiwan, ROC \\ ${ }^{2}$ Department of Civil and Disaster Prevention Engineering, National United University, Miaoli, Taiwan, ROC \\ ${ }^{3}$ Centre for Water Systems, College of Engineering, Mathematics and Physical Sciences, University of Exeter, Exeter, UK
}

Received 27 September 2013, revised 2 January 2014, accepted 11 February 2014

\begin{abstract}
Buildings often affect overland flow propagation in urban areas. Building walls change the direction and velocity of flow and can exclude interior spaces from flooding. However, water may intrude buildings when the flood level exceeds the height of protection. This study develops an inundation model that represents the resistance and the storage effects of buildings. This model was applied to central Taipei City, which is surrounded by the Danshui and Keelung Rivers. The inundation depth and extent were compared from models where the effects of buildings were included and excluded. Rainfall data from the Typhoon Nari event in 2001 was used in the simulation. The results showed that in the case where the effects of buildings were excluded inundation was underestimated in the metropolitan areas. Where the effects of buildings were considered in the model, the presented inundation model reproduces the inundation results more comparable with the observed flooding situation.
\end{abstract}

Key words: Inundation model, Building coverage ratio, Building storage effect, Roughness parameter adjustment

Citation: Huang, C. J., M. H. Hsu, A. S. Chen, and C. H. Chiu, 2014: Simulating the storage and the blockage effects of buildings in urban flood modeling. Terr. Atmos. Ocean. Sci., 25, 591-604, doi: 10.3319/TAO.2014.02.11.01(Hy)

\section{INTRODUCTION}

Urbanization is a global trend and rapid population growth and limited land resources have forced dense development in many cities. The increase in impervious areas leads to higher surface runoff and shorter concentration times. The existence of urban features, such as roads and buildings also changes the behavior of runoff. Therefore, rainfall-runoff processes in urban areas differ considerably from those in rural areas.

Inundation modeling in urban areas usually requires higher resolution topographic data to represent the complicated flow patterns around buildings. Advances in remote sensing techniques have enhanced the terrain representation for 2D flood modeling that has led to better modeling accuracy (Yu and Lane 2006a; Tsubaki and Fujita 2010; Erpicum et al. 2010). However, model implementations with these detailed topographic data in large watersheds require extraordinary computing resources, which limit their use in real-time flood forecasting. Among the approaches that

\footnotetext{
* Corresponding author

E-mail:mhhsu@ntu.edu.tw
}

have been developed to improve the efficiency of modeling, grid coarsening with averaged terrain elevation is the most straightforward method that can significantly speed up modeling. However, the building attributes that affect flood propagation are often lost during the simple coarsening process such that the modeling results fail to properly describe the detailed flow dynamics. Sub-grid models have been developed to account for building features by providing additional parameters to the coarse grid to regain the accuracy.

The IMPACT project (Alcrudo 2004) investigated several techniques to explicitly introduce the presence of buildings in the computation model, including the local friction based representation of buildings and obstacles; the bottom elevation in building presentation; and the vertical walls in the detailed mesh. Many studies adopted coarse grid porosity treatment in sub-grid models to simulate the flow behavior in fine grids. Yu and Lane (2006b) considered the topographic variability at sub-grid scales to describe the blockage and flux effects. This treatment obtained better flood prediction in urban areas than traditional approaches which only used Manning's roughness in the calibration; McMillan and 
Brasington (2007) derived the depth-dependent porosity function from the volume-depth relationship to provide the sub-grid parameter of coarse grid. With accurate porosity information this model can account for the blockage effects of micro-terrain variations in flood propagations using coarse grid resolution. Sanders et al. (2008) proposed a porous shallow water model in which the uniform drag coefficient is used to account for the impact of the sub-grid buildings on flow resistance. Two porosity parameters associated with asymmetric building shapes and distribution were applied to capture the flow directions in urban flooding. Chen et al. (2012a) assumed that impervious walls keep the areas inside buildings from flooding and introduced the building coverage ratio and conveyance reduction factors to reflect the building geometry and alignment attributes in coarse grid modeling. Chen et al. (2012b) further developed the multi-layered approach with these parameters to model the phenomenon of a building bisecting a coarse grid cell, preventing the flow moving between both sides of the building.

Buildings affect the flood propagation through shear resistance and drag resistance (Sanders et al. 2008). Green (2005) outlined how plants affect the flow resistance according to their distributions and shapes in a channel. Neelz and Pender (2007) investigated the roughness parameter of coarse-grid inundation models to describe the blockage effects by buildings and chose the appropriate roughness parameter by comparing the fine-grid model as a benchmark. The suggested roughness values in most research papers do not consider buildings and modifying roughness to reflect the increased resistance requires excessive trial and error process (Chen et al. 2012a).

In this study we developed an inundation model to simulate the blockage and storage effects of buildings on flow propagation in urban areas. If the water level outside a building stays below the entrance height, the walls and the raised entrance protect the building from flooding, which reduces the storage space in the computation grid cell located within. For this condition, buildings only affect the flooding because of the blockage effect. If the water level outside a building reaches the entrance height, the flood will flow into and be stored inside the building. The building storage effect may decrease the overland flow depth in this case. Meanwhile, the existence of buildings confines the conveyance width of flow and increases the surface resistance. We analyzed the surface roughness and suggested adjustment based on the building occupancy in a grid cell. The inundation model combined with the storm sewer model was applied to simulate the flooding in Taipei City.

\section{METHODOLOGY}

\subsection{Two-Dimensional Inundation Model}

Assuming the acceleration of water flow on land surface is small compared with the gravitation and friction, two-dimensional (2D) depth-averaged shallow water equations on land surface can be written as (Chang et al. 2000):

$$
\begin{aligned}
& \frac{\partial d}{\partial t}+\frac{\partial(u d)}{\partial x}+\frac{\partial(v d)}{\partial y}=q \\
& -\frac{\partial h}{\partial x}=u\left[\frac{n^{2}|u|}{d^{4 / 3}}\right] \\
& -\frac{\partial h}{\partial y}=v\left[\frac{n^{2}|v|}{d^{4 / 3}}\right]
\end{aligned}
$$

where Eq. (1) is the continuity equation and Eqs. (2) and (3) are momentum equations in Cartesian horizontal directions; $d$ is the depth of flow (m); $h$ is the water stage (m); $u$ and $v$ are the velocity component in the $x$ and $y$ directions $\left(\mathrm{m} \mathrm{s}^{-1}\right)$; $q$ is the source or the sink per unit area $\left(\mathrm{m} \mathrm{s}^{-1}\right)$ (the surcharge from manhole, the inflow of upstream catchment and the lateral inflow of channel are treated as the source and pumping discharge as sink); $n$ is Manning's roughness ( $\left.\mathrm{s} \mathrm{m}^{-1 / 3}\right)$.

The flow conditions in urban areas differ from rural plains due to the densely distributed buildings. To model flood dynamic in urban areas with existing buildings using coarse grid, buildings may occupy a partial grid cell area that reduces the cell storage capacity when the flood level is lower than the entrance height of buildings. In this study buildings are conceptualized as a region with the same geometry to a grid cell that is located at the cell's center, as shown in Fig. 1, without affecting the flux through the boundary shared with its neighbor cells. The occupancy of buildings in a cell area is defined as the building coverage ratio (BCR), $\alpha_{0}$, such that flood water can only distribute to $1-\alpha_{0}$ of cell area. Equation (1) is therefore modified as:

$$
\frac{\partial\left(1-\alpha_{0}\right) d}{\partial t}+\frac{\partial(u d)}{\partial x}+\frac{\partial(v d)}{\partial y}=q
$$

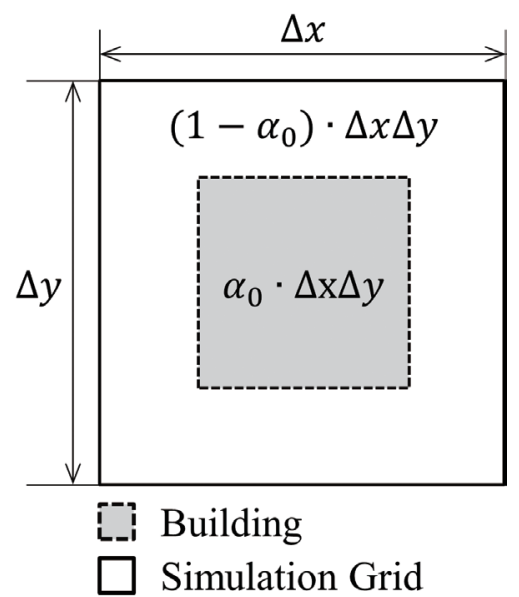

Fig. 1. Schematic of simulation grid containing buildings. 
In reality, solid building walls and the raised entrance or the temporary flood walls may keep the inside of buildings from flooding up to a threshold $d_{0}$. Once the flood level reaches the threshold, water starts flowing into buildings and filling the space inside. The discharge can be calculated using the broad crested weir formula, which can be converted as a sink term in the continuity equation as

$q_{t}=\frac{2}{3} \cdot \mu \cdot b \cdot(2 g)^{1 / 2} \cdot \frac{\left(d-d_{0}\right)^{3 / 2}}{\Delta x \cdot \Delta y}$

and Eq. (4) is rewritten as

$\frac{\partial\left(1-\alpha_{0}\right) d}{\partial t}+\frac{\partial(u d)}{\partial x}+\frac{\partial(v d)}{\partial y}=q-q_{t}$

where, $\mu$ is the coefficient of weir flow $(\mu=0.85), b$ is the width of building entrance $(\mathrm{m}), d_{0}$ is the threshold of building entrance height $(\mathrm{m}), q_{t}$ is the discharge per unit area entering building $\left(\mathrm{m} \mathrm{s}^{-1}\right)$.

By integrating $q_{t}$ with respect to time $\left(t_{0}\right.$ is the time of water as it starts to flow into the building), the total flood volume inside the building is estimated as $\int_{t_{0}}^{t} q_{t} \cdot d t$. If the flow interactions inside a computing cell are regarded as internal processes, substituting $q_{t}$ with $\partial\left(\int_{t_{0}}^{t} q_{t} \cdot d t\right) / \partial t$, and Eq. (6) can be rearranged as

$\frac{\partial\left(1-\alpha_{0}\right) d}{\partial t}+\frac{\partial\left(\int_{t_{0}}^{t} q_{t} \cdot d t\right)}{\partial t}+\frac{\partial(u d)}{\partial x}+\frac{\partial(v d)}{\partial y}=q$

Combining the first two terms on the left hand side and letting $\alpha^{\prime}=\int_{t_{0}}^{t} q_{t} \cdot d t / d$ and $\alpha=\alpha_{0}-\alpha^{\prime}$, an equation with the same form as Eq. (4) is derived

$\frac{\partial(1-\alpha) d}{\partial t}+\frac{\partial(u d)}{\partial x}+\frac{\partial(v d)}{\partial y}=q$

The flood volume inside a building is expressed as an equivalent area ratio $\alpha^{\prime}$ (Fig. 2). Ignoring the thickness of walls and the storage space inside buildings below the ground elevation, $\alpha^{\prime}$ is a value between 0 , when the flood depth never reaches the threshold $d_{0}$, and $\alpha_{0}$, when the water depth inside building reaches the same level as the flood outside the building. The dynamic change in $\alpha^{\prime}$ is irreversible during a simulation, meaning the water inside the building below $d_{0}$ is trapped and will not return outside the building.

In other words, $\alpha$ varies from $\alpha_{0}$, when the inside of the building is totally dry, to 0 , when the inner water level reaches the same as the outer one. For the latter, Eq. (8) is equivalent to Eq. (1) since no barrier stops the flow interaction between the outside and inside of the building. When the outer water level drops below $d_{0}, \alpha_{0}$ is applied to Eq. (8) until the water level raises above the threshold ( $\alpha$ may not be zero if the building inside is not fully filled before the outer water level drops below $d_{0}$ ).

\subsection{The Resistance Under the Blockage Effect of Buildings}

The total resistance $F$ within a computing cell includes the surface resistance $F^{\prime}$ along the flow paths and the building drag resistance $F^{\prime \prime}$ due to the blockage of buildings (i.e., $\left.F=F^{\prime}+F^{\prime \prime}\right)$.

The surface resistance is defined as the friction shearing stress on the ground surface area. The existence of buildings restricts the flow between buildings, which results in reduced friction forces due to a lower surface area $\left(1-\alpha_{0}\right) \cdot A$ :

$F^{\prime}=\tau_{w} \cdot\left(1-\alpha_{0}\right) \cdot A$

where, $\tau_{w}=\gamma \cdot d \cdot S_{f}$ is the friction shearing stress and $\gamma$ is the specify gravity of water. Replacing the friction slope $S_{f}$ with $\left(n_{o r i}^{2} \cdot V^{2}\right) / d^{4 / 3}$, where $V=\sqrt{u^{2}+v^{2}}, n_{\text {ori }}$ is the original Manning's roughness without considering buildings and substituting $\tau_{w}$ in Eq. (9), the reduced resistance force becomes:

$F^{\prime}=\gamma \cdot d \cdot \frac{n_{o r i}^{2} \cdot V^{2}}{d^{4 / 3}} \cdot\left(1-\alpha_{0}\right) \cdot A$

Building drag resistance forms as the overland flow is obstructed and it is a function of the submerged building area normal to the flow direction $\left(A_{\alpha}\right)$ :

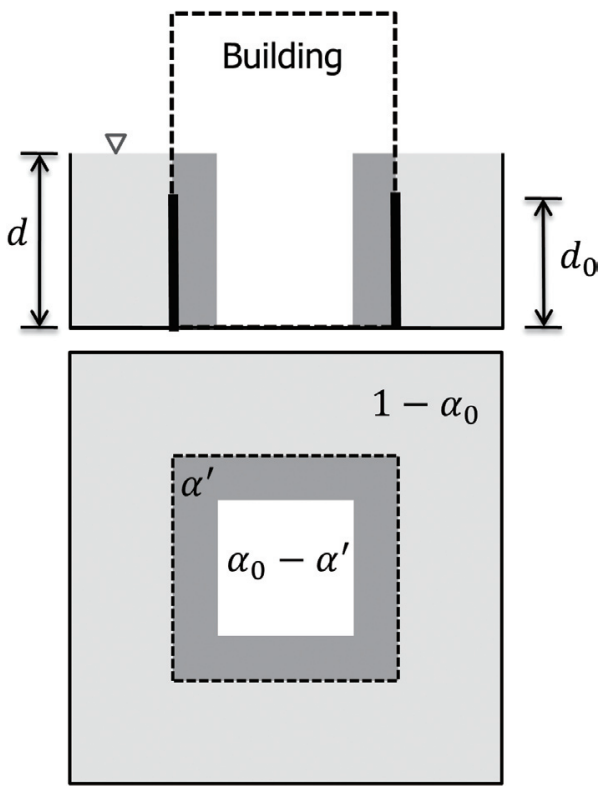

Fig. 2. The equivalent area ratio of inflow volume $\alpha^{\prime}$. 
$F^{\prime \prime}=\frac{1}{2} \cdot C_{D} \cdot \rho \cdot V^{2} \cdot A_{\alpha}$

where, $C_{D}$ is the building drag coefficient, $\rho$ is the density of water $\left(\mathrm{kg} \mathrm{m}^{-3}\right)$ and $A_{\alpha}$ is the submerged building area normal to the flow direction $\left(\mathrm{m}^{2}\right), A_{\alpha}=\sqrt{\alpha_{0} \cdot A} \cdot d$. The building drag resistance can be converted to the same form as the shear resistance applied to the total area:

$F^{\prime \prime}=\gamma \cdot d \cdot \frac{\left(n^{\prime \prime}\right)^{2} \cdot V^{2}}{d^{4 / 3}} \cdot A$

where, $n^{\prime \prime}$ is the roughness that represents the building drag resistance $\left(\mathrm{s} \mathrm{m}^{-1 / 3}\right)$.

From Eqs. (11) and (12) we can derive $n^{\prime \prime}$ as:

$n^{\prime \prime}=\sqrt{\frac{1}{2 g \sqrt{A}} \cdot C_{D} \cdot \alpha_{0}^{1 / 2}} \cdot d^{2 / 3}$

Azinfar and Kells (2008) measured building drag coefficients of different size obstructions in channels through hydraulic experiments and described $C_{D}$ as a function of the BCR,

$C_{D}=3.43\left(1-\sqrt{\alpha_{0}}\right)^{-2.31}$

Hence, $n^{\prime \prime}$ is derived as:

$n^{\prime \prime}=0.418 \cdot d^{2 / 3} \cdot A^{-1 / 4} \cdot \sqrt{\left(1-\sqrt{\alpha_{0}}\right)^{-2.31} \cdot \alpha_{0}^{1 / 2}}$

Figure 3 shows that assuming $A=1600 \mathrm{~m}^{2}, n^{\prime \prime}$ increases with the water depth more significantly when the BCR increases, which means higher depth will induce higher drag force due to the blockage of buildings. Higher BCR will also increase $n^{\prime \prime}$ in the same water depth.

\subsection{Roughness Adjustment}

Substituting Eqs. (10) and (12) into $F=F^{\prime}+F^{\prime \prime}$, we obtain the total friction force as

$$
\begin{gathered}
\gamma \cdot d \cdot \frac{n^{2} \cdot V^{2}}{d^{4 / 3}} \cdot A=\gamma \cdot d \cdot \frac{n_{o r i}^{2} \cdot V^{2}}{d^{4 / 3}} \cdot\left(1-\alpha_{0}\right) \cdot A+ \\
\gamma \cdot d \cdot \frac{\left(n^{\prime \prime}\right)^{2} \cdot V^{2}}{d^{4 / 3}} \cdot A
\end{gathered}
$$

Where, $n$ is the adjusted Manning's roughness for overland flow modeling that accounts for both the ground surface friction and the building shape resistance. Therefore, the roughness corresponding to the blockage effect is obtained.

$n=\sqrt{\left(1-\alpha_{0}\right) \cdot n_{o r i}^{2}+\left(n^{\prime \prime}\right)^{2}}$

Figure 4 shows the relationship between the adjusted roughness $n$, flood depth $d$ and BCR $\alpha_{0}$, assuming that $n_{\text {ori }}=0.2$ and $A=1600 \mathrm{~m}^{2}$. For lower flood depths the increased shape resistance is cancelled out by the reduced surface friction. When the flood depth rises, $n^{\prime \prime}$ grows at a much higher rate, as shown in Fig. 3, such that $n$ changes more quickly. Letting $n^{\prime \prime}=\sqrt{\alpha_{0}} \cdot n_{\text {ori }}$ in Eq. (15), we can determine the water depth $d_{n}$ as

$d_{n}=3.7 \cdot\left(1-\sqrt{\alpha_{0}}\right)^{1.73} \cdot\left(\alpha_{0} \cdot A\right)^{0.38} \cdot n_{\text {ori }}^{1.5}$

$d_{n}$ means the water depth when the adjusted roughness $n$ is equal to the original value $n_{\text {ori }}$. Table 1 lists the $d_{n}$ values that correspond to different BCR values for the given $n_{\text {ori }}=0.2$ and $A=1600 \mathrm{~m}^{2}$. For lower BCR values, $n$ is less sensitive to the change in flood depth so the increased building shape resistance has very little influence over the reduced

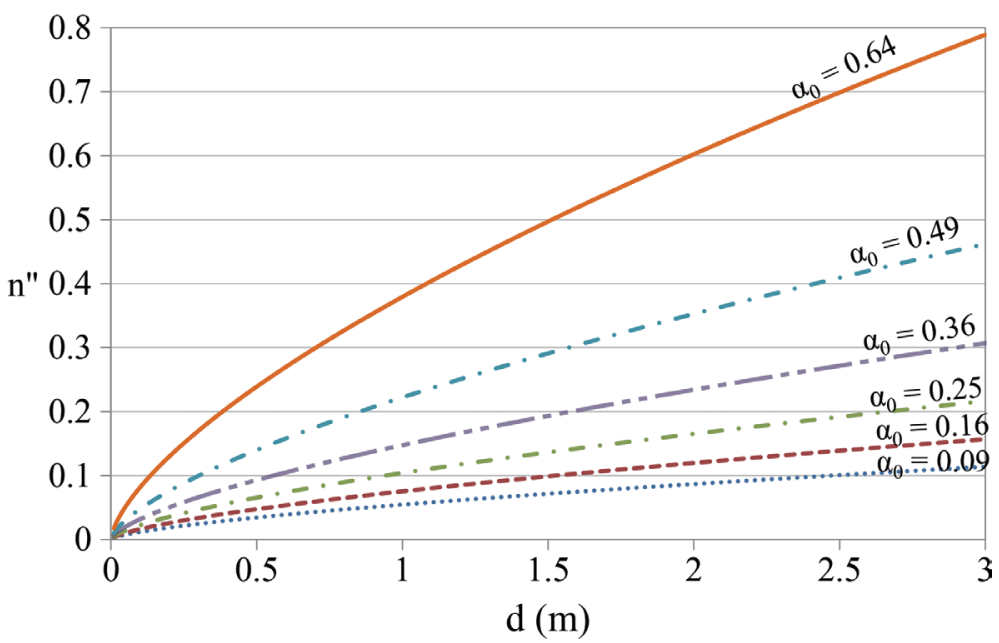

Fig. 3. Relationship of BCR and $n^{\prime \prime}$ in different water depths. 


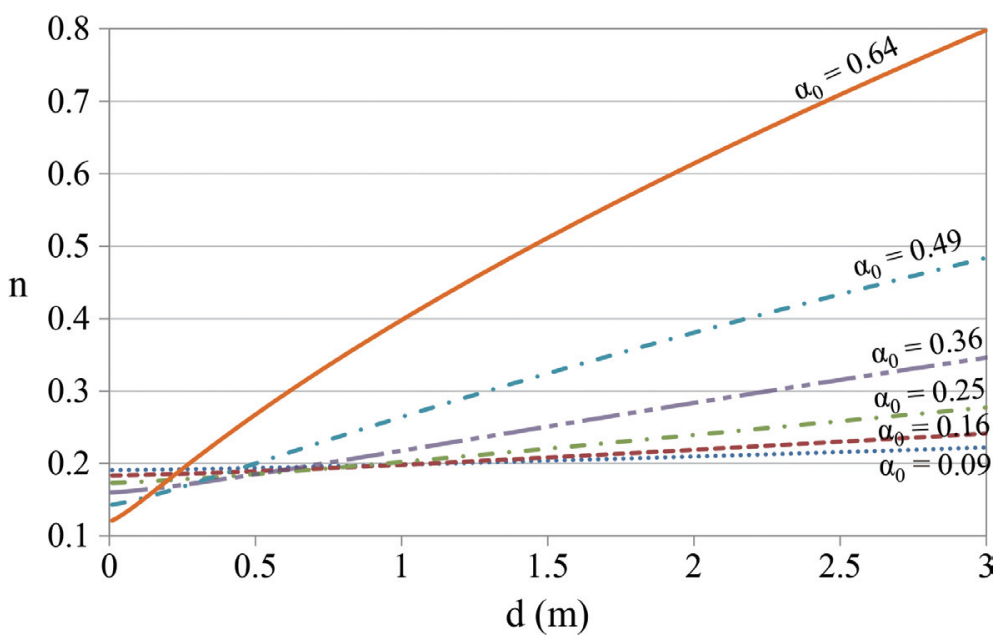

Fig. 4. Relationship of BCR and $n$ in different water depths.

Table 1. $d_{n}$ under different BCR values.

\begin{tabular}{cc}
\hline BCR & $\boldsymbol{d}_{\boldsymbol{n}}(\mathbf{m})$ \\
\hline 0.09 & 1.15 \\
0.16 & 1.09 \\
0.25 & 0.94 \\
0.36 & 0.73 \\
0.49 & 0.50 \\
0.64 & 0.27 \\
\hline
\end{tabular}

surface friction such that $d_{n}$ is more than $1 \mathrm{~m}$. For large BCR values the reduced weight of $n_{\text {ori }},\left(1-\alpha_{0}\right)$, results in $n^{\prime \prime}$ dominating the calculation of $n$ and $d_{n}$ decreases to 0.27 for the case that $\alpha_{0}=0.64$.

\section{RESULTS AND DISCUSSION}

\subsection{Evaluation of Model Performance}

Downtown Taipei City, located in northern Taiwan, was adopted as a case study for the model application. The area is densely populated and surrounded by the Danshui River and its tributaries, the Keelung and Sindian Rivers. High levees along the river protect the city against flooding up to 200 year return period. The topography of Taipei City contains mountainous areas in the southeast and lowlands in the northwest area (Fig. 5). The Taipei City Government built 25 drainage and pumping systems to cope with surface runoff caused by pluvial events.

Typhoon Nari swept through Taiwan with recordbreaking rainfall in northern Taiwan on 16 September 2001. Table 2 shows the total amount and peak intensity of rainfall records from gauges in downtown Taipei during Typhoon
Nari. The rainfall in the Nangang and Neihu neighborhood gauges accumulated more than $690 \mathrm{~mm}$ in $24 \mathrm{hrs}$. The peak intensity of most rain gauges exceeded the design standard (78 $\mathrm{mm} \mathrm{hr}^{-1}$ ) for the sewer systems in Taipei City. A levee breach occurred near pumping station No. 19 and floodwaters entered downtown Taipei with a peak discharge of $350 \mathrm{cms}$ from the Keelung River and submerged a wide area in Taipei city. The flood damaged pumping stations No. 13, 17, 18, 19, and 20 exacerbating the flooding condition.

We adopted the HEC-1 Model developed by the Hydrologic Engineering Center (1998) to calculate runoff from the upstream catchments as the lateral inflows of the 2D inundation model. The Storm Water Management Model (SWMM) (Huber and Dickinson 1988) was adopted to solve the sewer system in Downtown Taipei City. The discharges drained by pumping stations are considered as the lateral outflows from the model and the surcharges of manholes are regarded as point sources in the model (Chen et al. 2005).

We compared three settings for reflecting the building blockages and storage effects in urban flood modeling. Setting A only adopted the bare terrain elevation without roughness adjustment, which is the traditional approach that ignores the existence of building in urban flood modeling. Settings B and $\mathrm{C}$ used the BCR values and adjusted the roughness to represent the blockage effect. The difference between Setting $\mathrm{B}$ and $\mathrm{C}$ was the threshold of the building entrance heights. In Setting B, the heights were set at $99 \mathrm{~m}$ above ground elevation, which prevented the flood from entering the buildings such that no storage effect was simulated.

In Setting $\mathrm{C}$ we collected the building data from Downtown Taipei City and classified them into three categories, as shown in Fig. 6. Category 1 was traditional apartments with up to 5 floors and without elevators. Category 2 was apartments with 5 to 7 floors and an elevator. Category 3 was condominiums with more than 7 floors and an elevator. The thresholds $\left(d_{0}\right)$ of building entrance height for each 
category were set as $0.5,1$, and $2 \mathrm{~m}$, respectively, which allows buildings to store water when the flood depth was greater than the threshold.

All three settings used the same $40 \times 40 \mathrm{~m}$ simulation grid and the original Manning's roughness 0.2 of each grid cell. In settings B and C, the BCR values were calculated with the occupied area of buildings in each cell. The average BCR values of all districts listed in Table 3 are mean BCR values of total grids located in the districts. The Manning's roughness of each cell was modified according to Eq. (17) during the simulation.
The Taipei City Government (2001) surveyed the inundated area and delineated the flood extent with flood depths greater than $0.3 \mathrm{~m}$, shown in Fig. 7, which was estimated about 2154 ha. The lowland areas along the Keelung River in Nangang, Xinyi Songshan and Zhongshan Districts were inundated. Figures 8,9 , and 10 are the simulated flooded areas above $0.3 \mathrm{~m}$ of settings $\mathrm{A}, \mathrm{B}$, and $\mathrm{C}$, respectively, for the Typhoon Nari event. The simulated flooding area is consistent with the surveyed areas in Nangang, Xinyi and Songshan districts for all settings. The Zhongshan and Datong districts were only partly inundated in setting A but

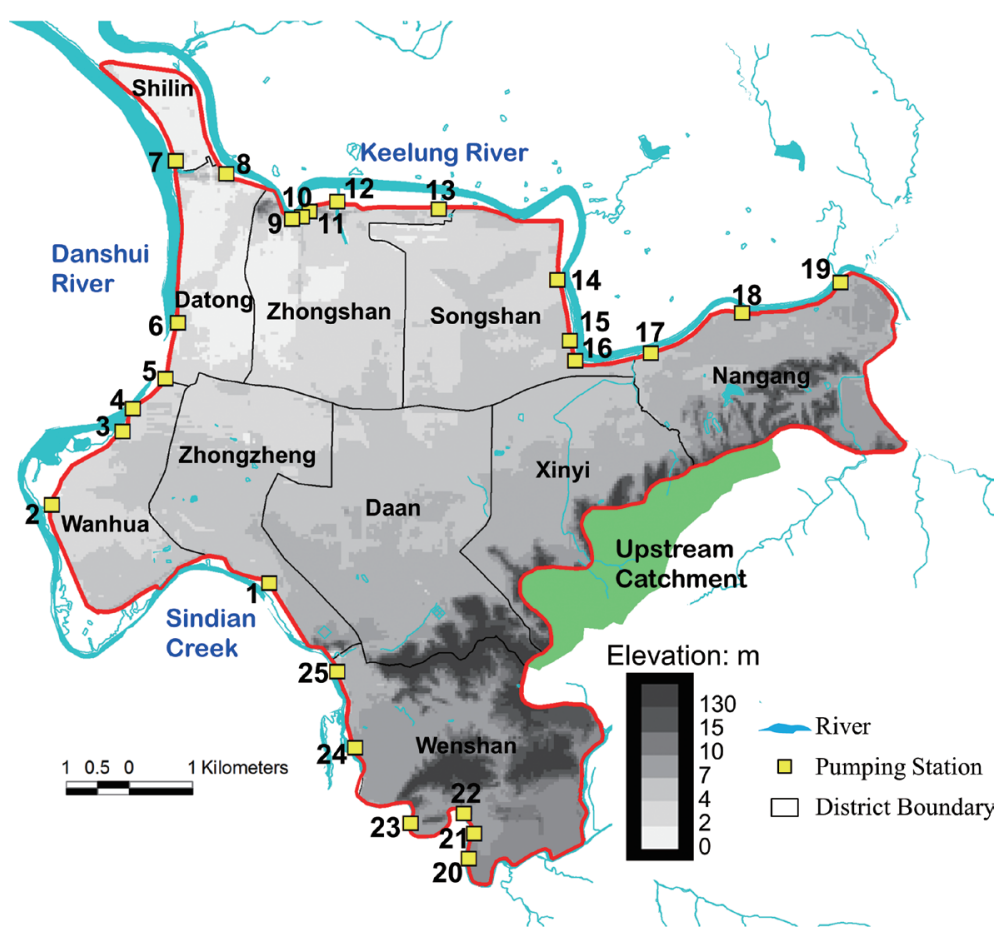

Fig. 5. Digital terrain model and districts of downtown Taipei.

Table 2. Total amount and peak intensity of rainfall in downtown Taipei.

\begin{tabular}{|c|c|c|}
\hline Rain gauge & Total Rainfall (mm) & Peak Intensity $\left(\mathrm{mm} \mathrm{hr}^{-1}\right)$ \\
\hline Shilin & 548.5 & 94.0 \\
\hline Sanchun & 526.5 & 68.0 \\
\hline Taipei & 593.5 & 77.0 \\
\hline Chungcheng Bridge & 613.0 & 95.0 \\
\hline Yunghon & 530.5 & 93.5 \\
\hline Muzha & 542.5 & 57.5 \\
\hline Xinyi & 504.5 & 84.5 \\
\hline Nangang & 733.5 & 105.0 \\
\hline Dazhi & 596.5 & 93.5 \\
\hline Neihu & 692.5 & 109.5 \\
\hline
\end{tabular}




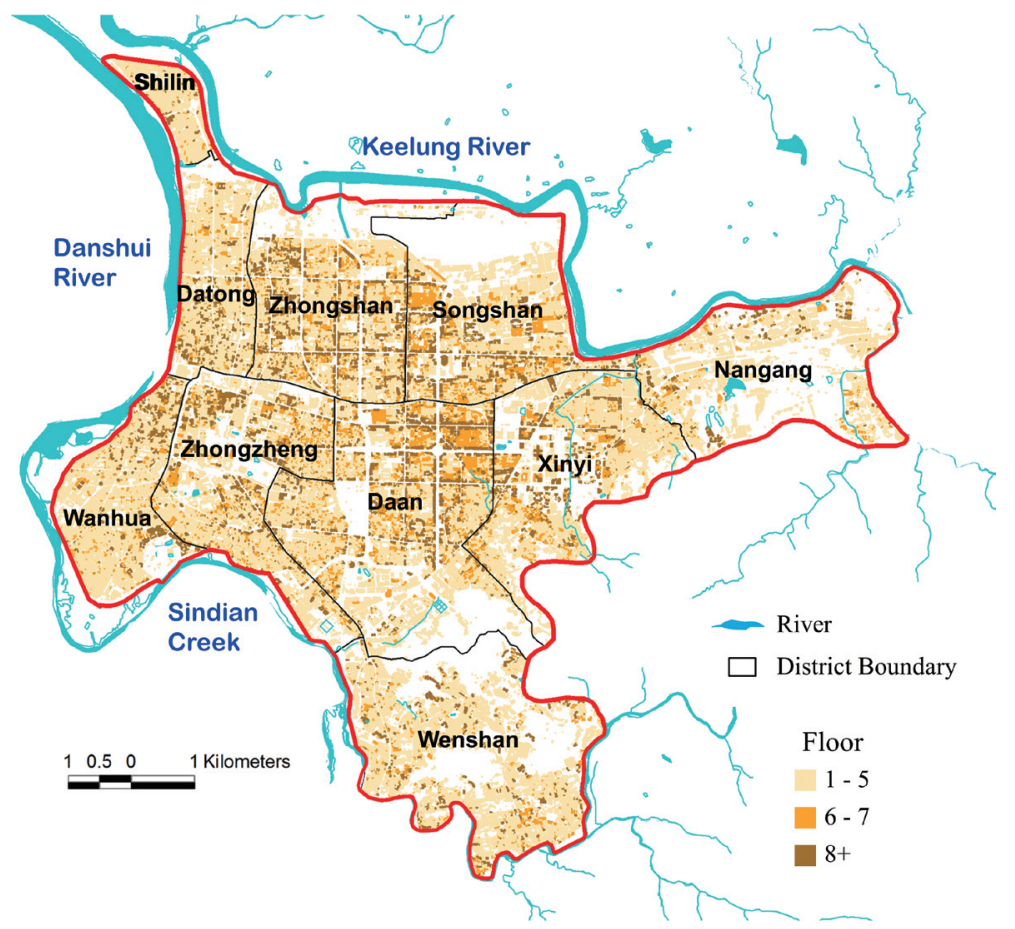

Table 3. Building coverage ratios of district in downtown Taipei.

\begin{tabular}{lc}
\hline \multicolumn{1}{c}{ District } & Average BCR $\boldsymbol{\alpha}_{\mathbf{0}}$ \\
\hline Shilin & 0.40 \\
Datong & 0.42 \\
Zhongshan & 0.32 \\
Songshan & 0.26 \\
Wanhua & 0.40 \\
Zhongzheng & 0.32 \\
Daan & 0.29 \\
Xinyi & 0.29 \\
Nangang & 0.18 \\
Wenshan & 0.21 \\
All & 0.31 \\
\hline
\end{tabular}

Fig. 6. The classification of building floors in downtown Taipei.

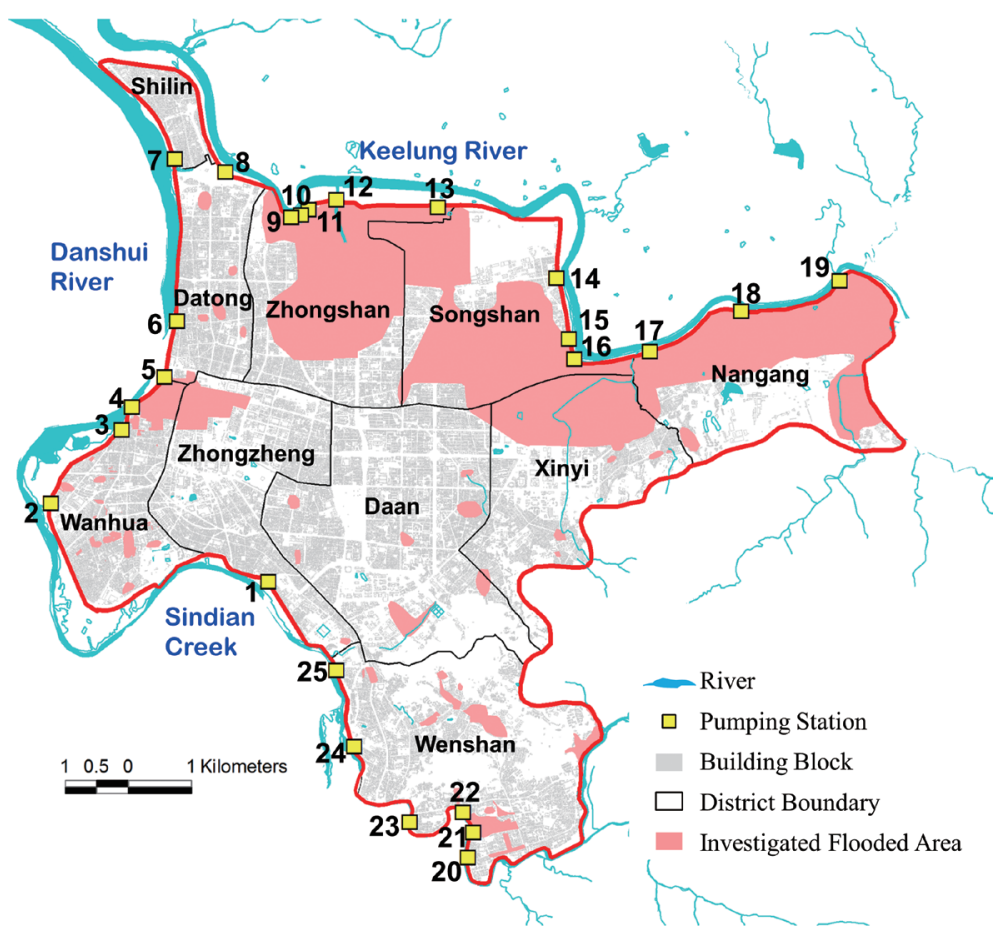

Fig. 7. Investigated flood extent of Typhoon Nari in downtown Taipei. 


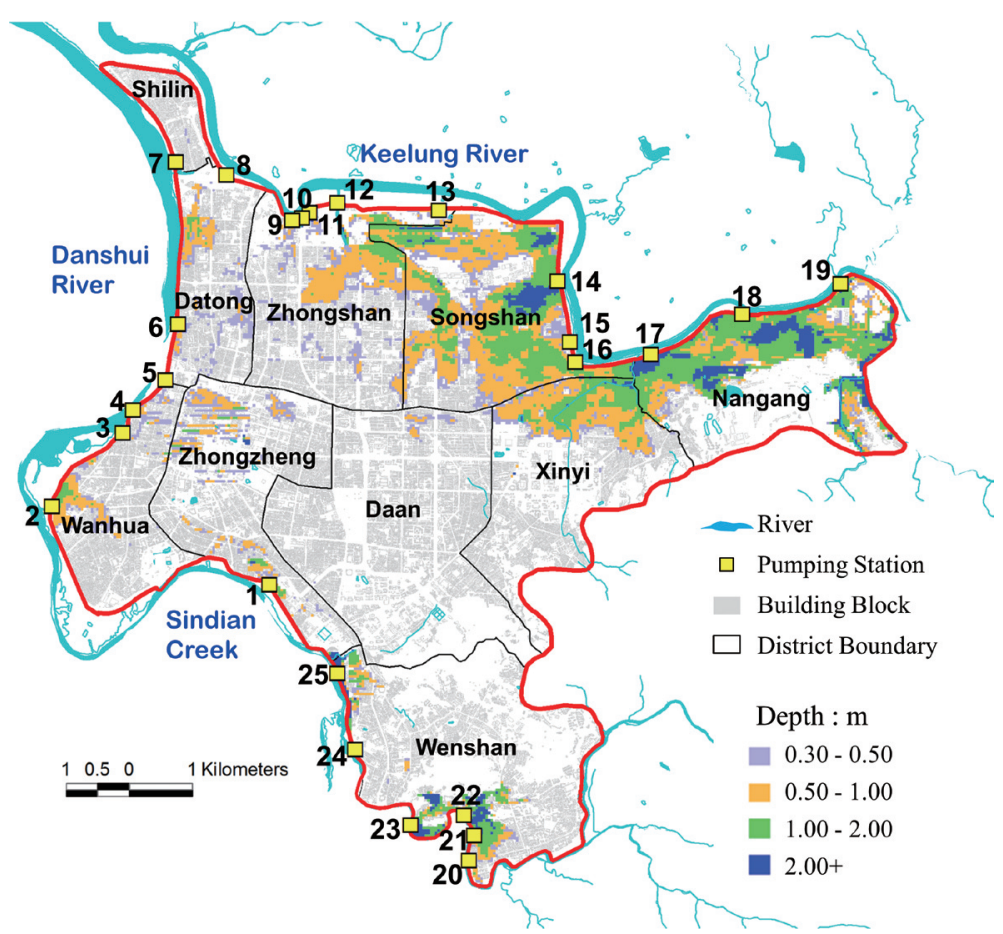

Fig. 8. Simulated flood areas of Typhoon Nari in downtown Taipei without building blockage effect (setting A).

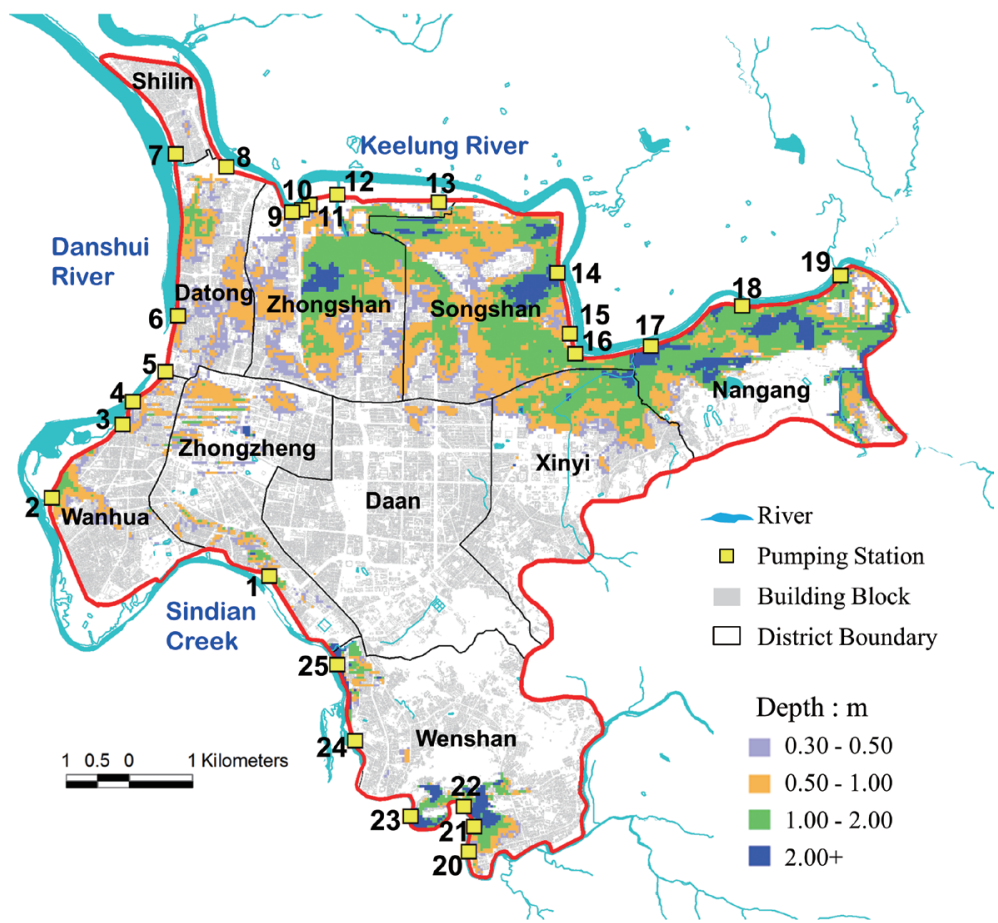

Fig. 9. Simulated flood areas of Typhoon Nari in downtown Taipei with building blockage effect (setting B). 


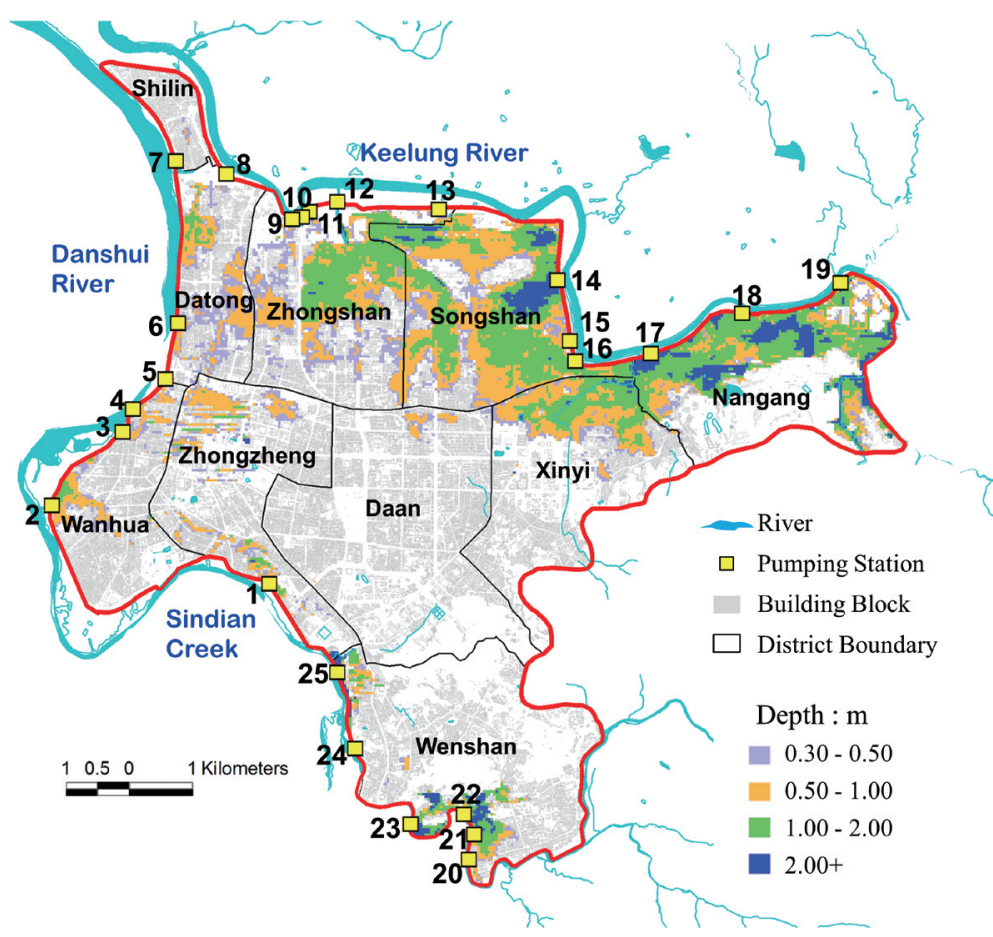

Fig. 10. Simulated flood areas of Typhoon Nari in downtown Taipei with building blockage and storage effect (setting C).

extremely flooded in settings B and C.

We used the quantified measurement between the investigated and simulated flood extents to represent the modeling results accuracy (Bates et al. 2005),

$P=\frac{A_{\text {inv }} \cap A_{\text {sim }}}{A_{\text {inv }} \cup A_{\text {sim }}}$

where, $A_{i n v}$ and $A_{\text {sim }}$ represent areas investigated to be inundated and simulated as inundated, respectively. $P$ is equal to 1 when the simulation flood extent exactly coincides with the investigated area and to 0 when no overlap exists. Note that the $A_{\text {sim }}$ in settings $\mathrm{B}$ and $\mathrm{C}$ also includes areas occupied by buildings. This ensured that $A_{\text {sim }}$ can be evaluated with the same standard in each setting.

The simulated flood areas, as shown in Table 4, for A, B, and $\mathrm{C}$ were 1785, 2284, and 2157 ha, respectively, while the investigated flood extent was 2154 ha. Details of the evaluation results and volume statistics are summarized in Table 5. Total flooded volume, which means the flood volumes outside buildings, are $12.08,10.78$, and $9.45 \times 10^{6} \mathrm{~m}^{3}$ in settings $\mathrm{A}, \mathrm{B}$, and $\mathrm{C}$. Total volumes in buildings is $2.5 \times 10^{6} \mathrm{~m}^{3}$ in setting $\mathrm{C}$. Ignoring buildings in setting A led to significant underestimation of the inundated area because a lot of inundation occurred at the locations were actually occupied by buildings, which were safeguarded by their elevated entrances and walls from flooding.

Settings $\mathrm{B}$ and $\mathrm{C}$ had $P$ values higher than setting A, indicating the proposed models which consider the building effects in urban areas, performed better than the model in setting A. The flooded areas in each water depth interval were larger than the ones in setting A because the water spread wider in settings $\mathrm{B}$ and $\mathrm{C}$ due to the existence of buildings, whereas the total final flood volume is smaller than setting A. In setting $\mathrm{C}$ the flooded areas in each interval were smaller than setting B because $20.9 \%$ of the final flood water volume was trapped in buildings due to the storage effect.

\subsection{Storage and Blockage Effects of Buildings}

The inundation areas of each district are shown in Table 6. The Nangang district had the smallest average $\mathrm{BCR}$, the inundated area above $0.3 \mathrm{~m}$ is 439 ha in setting A, 450 ha in setting B, and 448 ha in setting C. The difference in the inundated areas increased by about only 2.6 and $2.2 \%$ due to buildings. In contrast, the largest average BCR of 0.42 was in the Datong district, but the inundated areas of settings $A$ and $C$ differed from 75 to 148 ha, the variation in areas reached a very high value of $96.4 \%$. These results indicated that the blockage effect was more significant when the building occupancy on the surface was higher. In setting $\mathrm{B}$ the flooded areas changed dramatically higher in the Datong and Zhongshan districts because these areas were not severely inundated without considering the buildings in setting A. In the Nangang, Xinyi and Songshan districts, which were already widely inundated in setting A, flooded areas only slightly increased in setting B. In setting $\mathrm{C}$ part of the flood water exceeding the height of the given threshold was 
Table 4. Inundation area of Downtown Taipei City (unit: ha).

\begin{tabular}{crrr}
\hline Water depth $(\mathbf{m})$ & setting A & setting B & setting C \\
\hline $0.3-0.5$ & 368.64 & 418.72 & 404.00 \\
$0.5-1.0$ & 660.80 & 804.48 & 764.32 \\
$1.0-1.5$ & 390.88 & 538.40 & 524.64 \\
$1.5-2.0$ & 187.04 & 281.60 & 257.28 \\
above 2.0 & 177.76 & 241.12 & 206.56 \\
\hline Total Area & $\mathbf{1 7 8 5 . 1 2}$ & $\mathbf{2 2 8 4 . 3 2}$ & $\mathbf{2 1 5 6 . 8 0}$ \\
Model Accuracy $(P)$ & 0.59 & 0.65 & 0.72 \\
\hline
\end{tabular}

Table 5. Water volume of simulation results (unit: $10^{6} \mathrm{~m}^{3}$ ).

\begin{tabular}{lrrc}
\hline \multicolumn{1}{c}{ Model Setting } & \multicolumn{1}{c}{ A } & \multicolumn{1}{c}{ B } & \multicolumn{1}{c}{ C } \\
\hline Final flood volume outside buildings & 12.08 & 10.78 & 9.45 \\
Final flood volume inside buildings & 0.00 & 0.00 & 2.50 \\
Total outflow volume & 37.15 & 38.45 & 37.28 \\
\hline
\end{tabular}

Table 6. Inundation area of each districts of downtown Taipei (unit: ha).

\begin{tabular}{|c|c|c|c|c|c|c|c|c|c|}
\hline \multirow[b]{2}{*}{ Depth (m) } & \multicolumn{3}{|c|}{ Shilin } & \multicolumn{3}{|c|}{ Datong } & \multicolumn{3}{|c|}{ Zhongshan } \\
\hline & setting A & setting B & setting C & setting A & setting B & setting $\mathrm{C}$ & setting A & setting B & setting $\mathrm{C}$ \\
\hline $0.3-0.5$ & 1.60 & 2.88 & 2.88 & 42.24 & 68.64 & 69.44 & 74.24 & 113.92 & 106.24 \\
\hline $0.5-1.0$ & 0.32 & 0.80 & 0.80 & 29.28 & 74.08 & 67.52 & 88.16 & 153.12 & 123.20 \\
\hline $1.0-1.5$ & 0.16 & 0.32 & 0.32 & 3.84 & 14.08 & 10.72 & 19.36 & 104.64 & 85.92 \\
\hline $1.5-2.0$ & 0.00 & 0.00 & 0.00 & 0.00 & 0.64 & 0.32 & 2.24 & 52.32 & 38.08 \\
\hline above 2.0 & 0.00 & 0.00 & 0.00 & 0.00 & 0.00 & 0.00 & 3.04 & 23.52 & 4.96 \\
\hline \multirow[t]{2}{*}{ Total } & 2.08 & 4.00 & 4.00 & 75.36 & 157.44 & 148.00 & 187.04 & 447.52 & 358.40 \\
\hline & \multicolumn{3}{|c|}{ Songshan } & \multicolumn{3}{|c|}{ Wanhua } & \multicolumn{3}{|c|}{ Zhongzheng } \\
\hline Depth (m) & setting A & setting B & setting C & setting A & setting B & setting $C$ & setting A & setting B & setting C \\
\hline $0.3-0.5$ & 90.56 & 74.40 & 69.76 & 29.60 & 31.68 & 29.92 & 52.48 & 50.24 & 48.16 \\
\hline $0.5-1.0$ & 244.48 & 236.48 & 239.36 & 29.92 & 46.40 & 42.24 & 43.20 & 69.44 & 66.24 \\
\hline $1.0-1.5$ & 144.48 & 180.48 & 189.28 & 8.00 & 10.24 & 9.28 & 7.36 & 11.84 & 10.08 \\
\hline $1.5-2.0$ & 63.20 & 82.88 & 80.64 & 0.48 & 0.64 & 0.64 & 1.28 & 2.40 & 2.08 \\
\hline above 2.0 & 34.88 & 50.72 & 51.68 & 0.16 & 0.16 & 0.16 & 3.20 & 4.00 & 3.04 \\
\hline \multirow[t]{2}{*}{ Total } & 577.60 & 624.96 & 630.72 & 68.16 & 89.12 & 82.24 & 107.52 & 137.92 & 129.60 \\
\hline & \multicolumn{3}{|c|}{ Daan } & \multicolumn{3}{|c|}{ Xinyi } & \multicolumn{3}{|c|}{ Nangang } \\
\hline Depth (m) & setting A & setting B & setting $\mathrm{C}$ & setting A & setting $B$ & setting $C$ & setting A & setting B & setting $\mathrm{C}$ \\
\hline $0.3-0.5$ & 8.96 & 7.68 & 7.84 & 27.04 & 30.24 & 29.12 & 26.24 & 24.96 & 26.24 \\
\hline $0.5-1.0$ & 4.00 & 10.08 & 10.08 & 99.20 & 88.48 & 95.84 & 94.08 & 92.96 & 88.48 \\
\hline $1.0-1.5$ & 0.00 & 0.00 & 0.00 & 48.32 & 68.96 & 63.52 & 134.40 & 126.08 & 130.88 \\
\hline $1.5-2.0$ & 0.00 & 0.00 & 0.00 & 16.64 & 23.68 & 20.16 & 82.24 & 96.64 & 93.76 \\
\hline above 2.0 & 0.00 & 0.00 & 0.00 & 3.52 & 9.28 & 5.12 & 102.08 & 109.60 & 109.12 \\
\hline \multirow[t]{2}{*}{ Total } & 12.96 & 17.76 & 17.92 & 194.72 & 220.64 & 213.76 & 439.04 & 450.24 & 448.48 \\
\hline & \multicolumn{3}{|c|}{ Wenshan } & & & & & & \\
\hline Depth (m) & setting A & setting B & setting $\mathrm{C}$ & & & & & & \\
\hline $0.3-0.5$ & 15.68 & 14.08 & 14.40 & & & & & & \\
\hline $0.5-1.0$ & 28.16 & 32.64 & 30.56 & & & & & & \\
\hline $1.0-1.5$ & 24.96 & 21.76 & 24.64 & & & & & & \\
\hline $1.5-2.0$ & 20.96 & 22.40 & 21.60 & & & & & & \\
\hline above 2.0 & 30.88 & 43.84 & 32.48 & & & & & & \\
\hline Total & 120.64 & 134.72 & 123.68 & & & & & & \\
\hline
\end{tabular}


stored in buildings so that the flooded area was smaller than the one in setting B. These results indicate that the flood will be restrained to streets, propagated more quickly and induced severe inundation in further downstream areas due to the blockage effect of buildings.

Figures 11, 12, and 13 show the local inundation area in settings $\mathrm{A}, \mathrm{B}$, and $\mathrm{C}$, respectively. In setting $\mathrm{A}$, the flood concentrated to the lower areas because only the surface elevation was accounted for in the simulation. Simulation results from settings $B$ and $C$ show that flooding was confined by densely built buildings and propagated along streets, which reflected the physical environment in Taipei City more accurately than the results from setting A. The results from setting B show that the water depths were higher and the flood extent was larger because the flood was blocked outside buildings and no water depths were reported inside buildings. In setting $C$ the water depth near the east area in the figures exceeded the threshold and drained into buildings so the maximum flood depth significantly decreased and many buildings were full of water.

We selected three cells as checkpoints, i.e., Pt. 1, 2, and 3 in Fig. 11, to compare the flow behaviors under different building conditions. The BCRs and thresholds of each point are shown in Table 7. Figures 14 and 15 show the hydrographs of the water depth and $\alpha^{\prime}$ values at these checkpoints, respectively. Results of setting A indicate that the water depths outside of the building at all points were lower than threshold $0.5 \mathrm{~m}$ during whole simulation

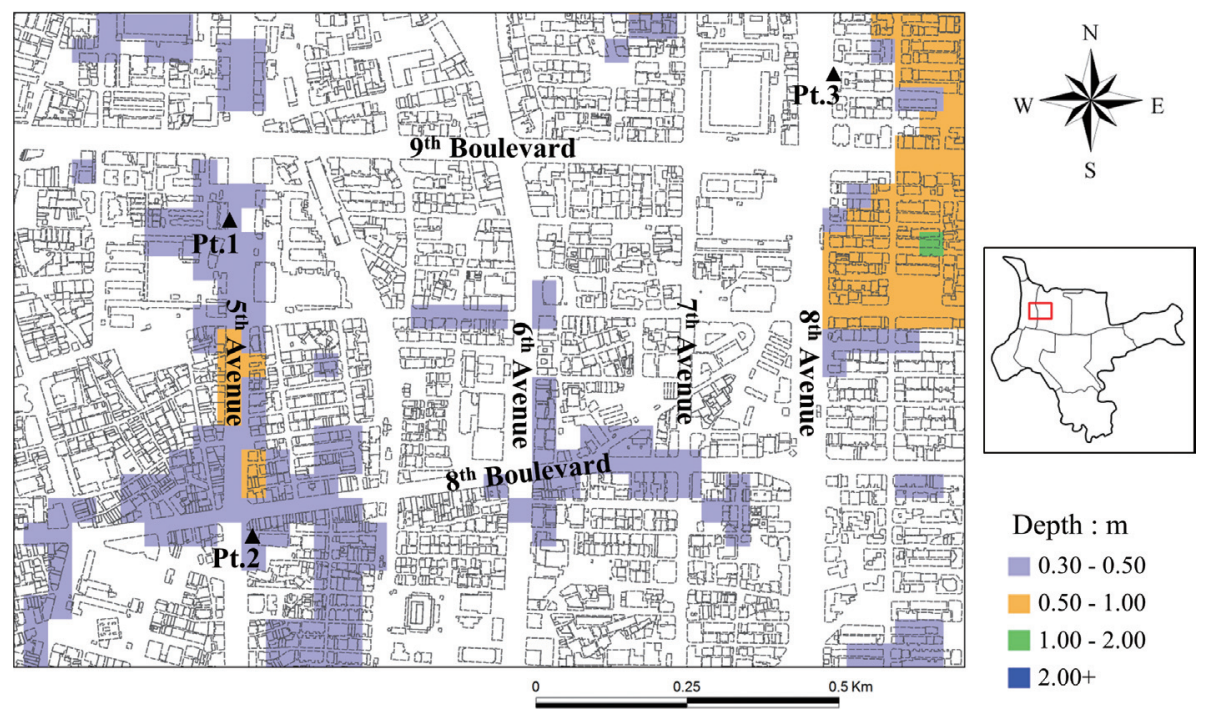

Fig. 11. Local simulated flood areas of Typhoon Nari without building blockage effect (setting A).

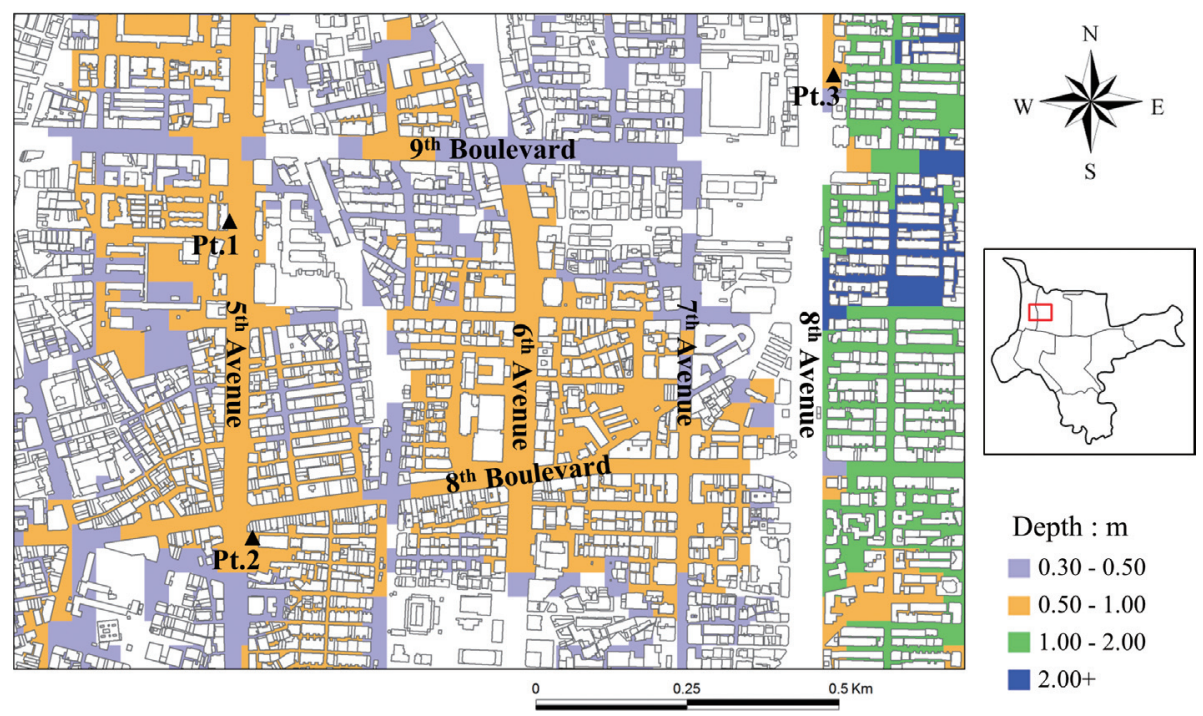

Fig. 12. Local simulated flood areas of Typhoon Nari with building blockage effect (setting B). 

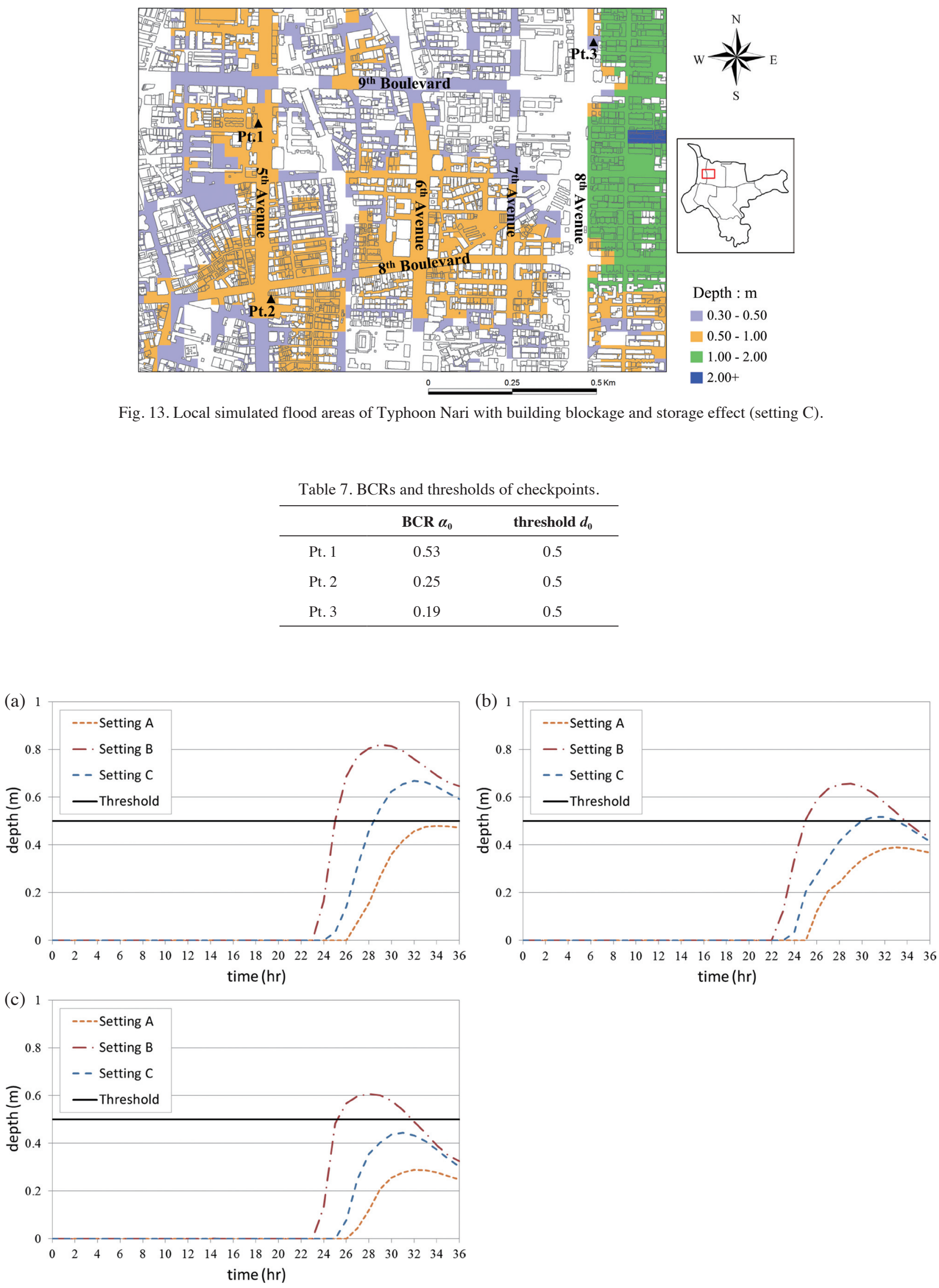

Fig. 14. The water depth at, (a) Pt. 1, (b) Pt. 2, and (c) Pt. 3. 


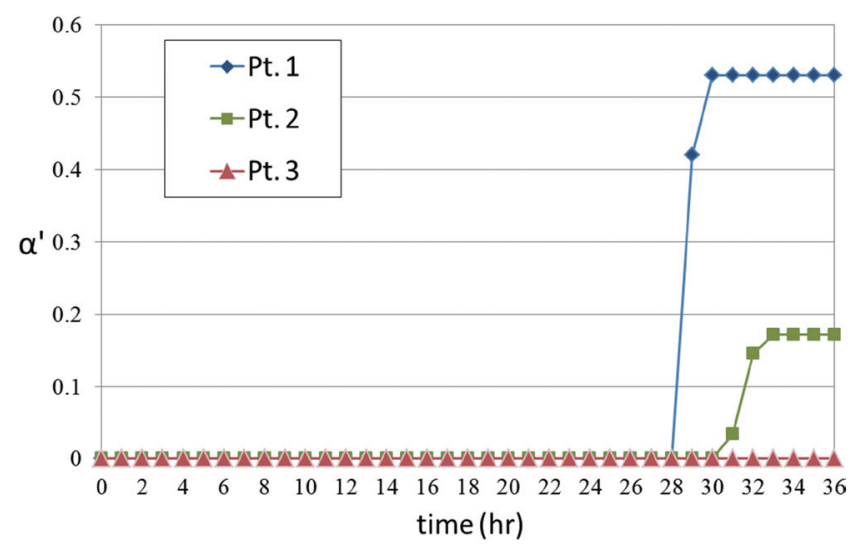

Fig. 15. Variation of $\alpha^{\prime}$ at Pt. 1, 2, and 3 in setting C.

process. While the building blockage effect was considered, the existence of buildings reduced the conveyance area of surface runoff in setting B such that the water depths increased rapidly and reached the maximum value about 4 hours earlier than setting A.

When the water depth at Pt. 1 reached the threshold of the building in setting $\mathrm{C}$, the surface runoff started flowing into buildings and the maximum water depths were significantly lower than setting B due to the storage effects of the buildings. The flood rapidly propagated and accumulated in the lowland area near to Pt. 1 so $\alpha^{\prime}$ in Fig. 15 quickly increased from 0 to 0.53 because the buildings were full of water within $2 \mathrm{hrs}$.

At Pt. 2 the water depth outside of the buildings at B reached the threshold $d_{0}$ in the $30^{\text {th }} \mathrm{hr}$. The $\alpha^{\prime}$ in Fig. 15 started to increase gradually to 0.17 and remained constant after the $33^{\text {th }} \mathrm{hr}$, which indicated the inside of the buildings were only partially filled by water, because the water depth reduced back below $d_{0}$ soon before the space was fully filled. At Pt. 3 the water depth is always lower than the threshold so $\alpha^{\prime}$ remained 0 .

From the results we can conclude that urban flood depths outside buildings increased rapidly to a higher stage due to the blockage effect of buildings in settings B and C. The maximum depth also appeared earlier, which indicates a flash flood in urban areas will cause higher impact because of the rapidly rising water level and quick flood propagation downstream.

\section{CONCLUSION}

An inundation model was developed to represent the effects of building blockages and storage in urban areas. In this paper we proposed a Manning's roughness modification method according to the blockage effect of buildings and considered the storage effects when water reaches the threshold of buildings. We also derived the flood depths when the increased building shape resistance dominates the reduced surface friction. The simulation results from the Nari Typhoon event indicated that the proposed model, using the BCR, the modified Manning's roughness and consideration of the storage effects can produce more accurate results in urban inundation modeling.

Acknowledgments The authors are grateful to the Central Weather Bureau and the Water Resources Agency for providing valuable information and historical records. We also appreciate Dr. Michael Hammond's help in providing suggestions about this paper.

\section{REFERENCES}

Alcrudo, F., 2004: Mathematical modelling techniques for flood propagation in urban areas. IMPACT Project technical report, $34 \mathrm{pp}$.

Azinfar, H. and J. A. Kells, 2008: Backwater prediction due to the blockage caused by a single, submerged spur dike in an open channel. J. Hydraul. Eng., 134, 1153-1157, doi: 10.1061/(Asce)0733-9429(2008)134:8(1153). [Link]

Bates, P. D., R. J. Dawson, J. W. Hall, M. S. Horritt, R. J. Nicholls, J. Wicks, and M. A. A. M. Hassan, 2005: Simplified two-dimensional numerical modelling of coastal flooding and example applications. Coast. Eng., 52, 793-810, doi: 10.1016/j.coastaleng.2005.06.001. [Link]

Chang, T. J., M. H. Hsu, W. H. Teng, and C. J. Huang, 2000: A GIS-assisted distributed watershed model for simulating flooding and inundation. J. Am. Water Resour. Assoc., 36, 975-988, doi: 10.1111/j.1752-1688.2000. tb05703.x. [Link]

Chen, A. S., B. Evans, S. Djordjević, and D. A. Savić, 2012a: A coarse-grid approach to representing building blockage effects in 2D urban flood modelling. J. Hydrol., 426427, 1-16, doi: 10.1016/J.Jhydrol.2012.01.007. [Link]

Chen, A. S., B. Evans, S. Djordjević, and D. A. Savić, 2012b: Multi-layered coarse grid modelling in 2D urban flood simulations. J. Hydrol., 470-471, 1-11, doi: 10.1016/j.jhydrol.2012.06.022. [Link]

Chen, A. S., M. H. Hsu, T. S. Chen, and T. J. Chang, 2005: An integrated inundation model for highly developed urban areas. Water Sci. Technol., 51, 221-229.

Erpicum, S., B. Dewals, P. Archambeau, S. Detrembleur, and M. Pirotton, 2010: Detailed inundation modelling using high resolution DEMs. Eng. Appl. Comp. Fluid., 2, 196208. Available at http://hdl.handle.net/2268/28186.

Green, J. C., 2005: Modelling flow resistance in vegetated streams: Review and development of new theory. $H y$ drol.Process., 19, 1245-1259, doi: 10.1002/Hyp.5564. [Link]

Huber, W.C. and R. E. Dickinson, 1988: Storm Water Management Model, Version 4: User's Manual, U. S. Environmental Protection Agency, Athens, Georgia.

Hydrologic Engineering Center, 1998: HEC-1 Flood 
Hydrograph Package User's Manual, US Army Corps of Engineers, Davis, California.

McMillan, H. K. and J. Brasington, 2007: Reduced complexity strategies for modelling urban floodplain inundation. Geomorphology, 90, 226-243, doi: 10.1016/j. geomorph.2006.10.031. [Link]

Neelz, S. and G. Pender, 2007: Parameterisation of SquareGrid Hydrodynamic Models of Inundation in the Urban Area. Proceedings of the Congress - International Association for Hydraulic Research, Vol. 1, Corila , Venice, $41 \mathrm{pp}$.

Sanders, B. F., J. E. Schubert, and H. A. Gallegos, 2008: Integral formulation of shallow-water equations with anisotropic porosity for urban flood modeling. J. Hydrol., 362, 19-38, doi: 10.1016/j.jhydrol.2008.08.009. [Link]
Taipei City Government, 2001: The reconstruction plan for the damage caused by typhoon Nari. Taipei City Government, Taipei, Taiwan.

Tsubaki, R. and I. Fujita, 2010: Unstructured grid generation using LiDAR data for urban flood inundation modelling. Hydrol. Process., 24, 1404-1420, doi: 10.1002/ Hyp.7608. [Link]

Yu, D. and S. N. Lane, 2006a: Urban fluvial flood modelling using a two-dimensional diffusion-wave treatment, part 1: Mesh resolution effects. Hydrol. Process., 20, 1541-1565, doi: 10.1002/Hyp.5935. [Link]

Yu, D. and S. N. Lane, 2006b: Urban fluvial flood modelling using a two-dimensional diffusion-wave treatment, part 2: Development of a sub-grid-scale treatment. Hydrol. Process., 20, 1567-1583, doi: 10.1002/ Hyp.5936. [Link] 